\title{
MÚSICA COMO AIA DA VONTADE Ensaio sobre a leitura wagneriana de Schopenhauer
}

\author{
Márcio Benchimol Barros* \\ benchimolbarros@gmail.com
}

RESUMO O ano de 1851 marca o primeiro contato de Richard Wagner com a filosofia de Schopenhauer, logo seguido por sua proclamada e algo surpreendente "conversão" ao schopenhauerianismo. Vinte anos depois, essa adesão é reafirmada em "Beethoven", escrito festivo que contém um esboço de uma filosofia da música, apresentada pelo compositor como fundamentada na estética schopenhaueriana e que terá grande influência na elaboração da noção do dionisíaco, tal como aparece em "O nascimento da Tragédia", de Nietzsche. Meu trabalho pretende, em primeiro lugar, investigar em que medida a estética musical esboçada em "Beethoven" é de fato compativel com as teses estéticas de "O mundo como Vontade e representação". A constatação de certas incongruências entre as duas concepções estéticas dá então oportunidade a reflexões sobre o caráter das relações entre Wagner, Schopenhauer e o jovem Nietzsche.

Palavras-chave Música, estética, Wagner, Schopenhauer, Nietzsche

ABSTRACT In the year 1851, Richard Wagner had his first contact with the philosophy of Schopenhauer, a fact that was followed soon by his proclaimed and somewhat surprising "conversion" to schopenhauerianism. Tweny years later, his debt to Schopenhauer is reaffirmed in "Beethoven", a comemorative writing in which are to be found the outlines of a philosophy of music-claimed by the composer to be based on Schopenhauer's aesthetics - that had great

* Professor assistente doutor na Unesp, Campus de Marília, Departamento de Filosofia. Artigo recebido em 19/10/2010 e aprovado em 20/5/2011.

KRITERION, Belo Horizonte, nº 125, Jun./2012, p. 179-193. 
influence in Nietzsche's theoretical elaboration of the dionysiac, as it appears in "The birth of Tragedy". My work aims primarily at investigating to what extent the musical aesthetics outlined in "Beethoven" is actually compatible with that presented in "The world as Will and representation". The pointing out of remarkable differences between the two aesthetic conceptions gives then rise to some reflexions concerning the character of the relations between Wagner, Schopenhauer and the young Nietzsche.

Keywords Music, aesthetics, Wagner, Schopenhauer, Nietzsche

Que Nietzsche escreve seu $O$ Nascimento da Tragédia sobre forte influência de Schopenhauer e Wagner é algo perfeitamente claro a todos. Mas tamanha claridade poderá eventualmente ofuscar um delicado jogo de chiaroscuro que apenas ao olho paciente e isento da crítica se revela. De fato, entre personagens tão densas e complexas não se deve esperar encontrar relações por demais definidas, e, em se tratando destas personagens, é demonstração de prudência ater-se às nuances, pois as nuances são amiúde mais importantes (e mais interessantes) que os fatos - e quem perde a nuance corre o risco de perder totalmente o fato.

No que se refere à ligação do jovem Nietzsche a Schopenhauer, já há muito se percebeu o quanto $O$ nascimento da Tragédia, apesar de toda a sua inegável dívida para com a metafísica da Vontade, correspondeu a uma tentativa consciente de superação do pessimismo schopenhaueriano, apresentando-se mesmo como refutação da interpretação pessimista da Tragédia grega dada pelo autor de $O$ Mundo como Vontade e representação. "A afirmação dionisíaca (Dionysische Bejahung)", diz Georges Goedert, "sucedeu à doutrina da negação da vontade de vida como o dia à noite, como seu oposto e superação"'.

Como se sabe, é através da ideia do dionisíaco que Nietzsche nega a interpretação schopenhaueriana da Tragédia grega como expressão estética da auto-negação moral da Vontade e como obra de arte máxima do pessimismo metafísico. E é também esta ideia que dá alento a suas esperanças juvenis de um renascimento de uma cultura trágica e afirmadora da vida a partir dos escombros da civilização socrática, esperanças estas não apenas ensejadas 
pela arte de Wagner, mas com este compartilhadas e nascidas sob direta influência do compositor. As filosofias de Kant e Schopenhauer, pensa o jovem Nietzsche, marcariam os limites máximos desta civilização, enquanto que música wagneriana traria as alvíssaras do inexorável ressurgimento do espírito dionisíaco e da obra de arte trágica² ${ }^{2}$.

Mas a importância de Wagner no que concerne ao dionisíaco nietzscheano é ainda mais funda, descendo mesmo ao nível de sua elaboração teórica. Pois, ainda que esta noção, estranha ao pensamento de Schopenhauer, tenha seguros antecedentes em Hölderlin e Friedrich Schlegel, é o pensamento estético de Wagner que, como veremos, permite sua absorção no seio de uma concepção filosófica da música, tal como ocorre em $O$ nascimento da Tragédia.

Sob esta perspectiva, podemos concluir que a ligação de Nietzsche a Wagner não se explica apenas pela declarada adesão deste à filosofia de Schopenhauer, muito embora esta circunstância tenha desempenhado um papel não negligenciável na aproximação entre ambos. De fato, percebemos que Wagner atrai Nietzsche também precisamente no que ele possui de não schopenhaueriano, naquilo que ele representa como possibilidade de superação do schopenhauerianismo. O jovem Nietzsche necessita de Wagner não tanto como representante estético do pensamento de Schopenhauer, mas, por assim dizer, muito mais como antídoto às consequências deste pensamento no que concerne ao problema do valor da existência.

A tarefa que me proponho neste escrito é a de investigar este elemento não schopenhaueriano do pensamento de Wagner, especificamente no que tange à estética musical, lançando assim talvez uma nova luz sobre o caráter de sua ligação ao pensador de Frankfurt. Quiçá também alguma nova sombra...

Não há como negar a importância que a filosofia de Schopenhauer teve para Wagner, nem talvez como superestimar o impacto que essa filosofia teve em sua própria maneira de pensar. Testemunha este impacto a notável distância que há entre Schopenhauer e autores como Proudhom, Bakunin e Feuerbach, que detinham a predileção do compositor até 1851, ano que marca seu encontro com $O$ mundo como Vontade e Representação. Como é sabido, Wagner, a partir de então, abandona o ideário socialista e anarquista para aderir entusiasticamente ao schopenhauerianismo, filosofia que abraça como representando sua própria visão de mundo. 
Mas para nossos propósitos importa muito mais perceber como se dá esta adesão no campo específico - e para Wagner evidentemente decisivo - da estética musical. Neste terreno particular, sob um aspecto de grande importância, Schopenhauer veio-lhe particularmente a calhar, pois possibilitou ao compositor a resolução filosófica de um paradoxo teórico em que sua criação estava enredada. Seja-me permitido introduzi-lo por meio de brevíssimas considerações sobre o lugar e o papel assumido pela arte, e especificamente pela música, no contexto cultural do romantismo.

A crítica romântica à razão setecentista, com sua ênfase na sensibilidade e no sentimento, traz para a arte do século XIX um chamamento às mais altas e urgentes tarefas: sensível por definição e por excelência, a arte aparece como a atividade espiritual mais próxima de todos os aspectos humanos negligenciados pela racionalidade iluminista e como porta-voz de todas as obscuras potências da alma que ali não puderam encontrar guarida. Neste contexto, a música adquire posição preponderante: sua evidente inaptidão para representar ou reproduzir o mundo exterior a torna a mais independente das artes em relação aos parâmetros racionais que nele se manifestam e, por isso mesmo, supunhase, a mais intimamente conectada com a interioridade da alma humana. Assim, aquilo que outrora podia ser visto como sua desvantagem frente às artes visuais (a saber, sua incapacidade para reproduzir o mundo empírico), agora é o símbolo de sua grande prerrogativa, a de servir de canal de expressão à tempestuosa alma romântica: na independência do som em relação ao mundo exterior essa alma torturada vislumbra sua possibilidade de máxima expansão e liberdade.

Em relação a esta concepção, porém, a chamada música programática ${ }^{3}$, cujo desenvolvimento por Berlioz e Liszt é pressuposição histórica do drama musical wagneriano, parece estar em contradição. Pois na tentativa aí implicada de pintar sonoramente cenas históricas, paisagens ou situações determinadas parece voltar a selar-se o compromisso da música com o mundo empírico, reafirmando-se sua dependência realtivamente à esfera da representação em geral. Restava, portanto, explicar como se podia partir de uma concepção de música como arte absolutamente não-representativa e chegar-se a uma arte musical pretensamente capaz de adequar-se a aspectos da realidade empírica, programa' ('Programm-Musik') significa que uma composição não mais deseja ser compreendida de forma puramente musical, 'absoluta', mas sim através de suas mais ou menos claras referências literárias e extra-musicais." (Munique, Drömersche Verlagsanstalt Th. Knaur, 1968, p. 391). Assim, é música à qual o compositor deliberadamente associa um conteúdo representacional passível de ser ou imaginado durante audição, ou mesmo visto, como no caso da ópera e do drama musical. 
ou mesmo de suscitar representações imaginativas. A resposta a este importuno dilema Wagner a encontrou pronta em Schopenhauer.

Em $O$ mundo como Vontade e representação, a arte toma explicitamente o lugar que o século XVIII concedeu à razão como via de acesso à verdade. A razão não pode apreender a coisa-em-si porque é somente um instrumento desta coisa-em-si, ou seja, da Vontade, essência metafísica e pré-racional do mundo e da qual este é apenas o fenômeno projetado na tela do espaço e do tempo. Sua serventia é exatamente a de tecer essa tela unindo os fios espaço-temporais segundo o princípio da causalidade e demais modalidades do princípio de razão suficiente. Mas a tela e a imagem que nela se forma, o mundo, não são senão o anteparo que nos impede de contemplar a verdadeira realidade. Apenas quando, absortos na contemplação estética, deixamos de seguir a trama do princípio de razão, quando abandonamos causalidade, conceitos e todos os esteios pelos quais o pensamento racional nos mantém presos ao mundo empírico, nos é dado vislumbrar, como que "por um buraco no manto dos fenômenos" (como dirá ironicamente Nietzsche), o permanente e incondicionado, jazendo eternamente para além de espaço e tempo. Através da beleza, um objeto se revela como mais que ele próprio: eis aí a natureza do fenômeno estético. Causalidade e conceito não são suficientes para compreendê-lo porque ele se destacou da trama do mundo para tornar-se expressão daquilo que subjaz a esta trama.

Mas, ao contrário do que ocorre nas artes plásticas, nas quais a Vontade se revela em seus aspectos isolados - através das ideias -, na música ela se mostra imediatamente em seu todo. Através do fenômeno absolutamente constitutivo do discurso musical que é a dissonância, a Vontade se revela em seu caráter essencial de eterno conflito consigo mesma, como inextinguível anseio a exigir satisfação e prazer, estados que na linguagem musical são simbolizados pela consonância. Mas se toda a satisfação da Vontade é seguida pela reposição do anelo e da carência, também a consonância é um repouso momentâneo que há de gerar a partir de si mesma a dissonância e, com isso, a continuidade do discurso musical. Assim, se a música não pode representar diretamente nada do mundo objetivo exterior, ela é como uma janela pela qual podemos contemplar com pleno gozo estético toda a extensão de nosso mundo subjetivo interior, no qual a Vontade se manifesta imediatamente. Através das relações harmônicas e rítmicas entre os sons cifra-se toda a escala cromática dos sentimentos humanos, da dor ao prazer, passando pela angústia, a coragem, o temor o tédio e a resignação. Mas, como a essência profunda de nosso mundo interior é a mesma que também subjaz ao mundo empírico, a saber, a Vontade, explica-se como a mesma música, em que vemos refletidas 
essas particularizações da Vontade que são nossos sentimentos, também nos pode sugerir aspectos particulares do mudo empírico:

Essa íntima referência da música à essência verdadeira de todas as coisas explica o fato de, quando soa uma música que combina com uma cena, ação, acontecimento, cercania, como que nos revela o sentido mais misterioso dos mesmos, entrando em cena como o comentário mais correto e distinto deles. De maneira similar, quando alguém se entrega por inteiro à impressão de uma sinfonia, é como se visse desfilar diante de si todos os eventos possíveis da vida e do mundo.... ${ }^{4}$

É dessa base filosófica que Wagner explicitamente lança mão, em seu Beethoven, para explicar a problemática adequação entre música e representações visuais e conceituais pressuposta pelo seu próprio drama musical, bem como por toda a música programática romântica, distinguindo-a da música meramente descritiva, daquela, vale dizer, que pretende alcançar tal adequação mediante algum tipo de imitação do mundo objetivo. A música autêntica, argumenta Wagner, não representa o mundo objetivo nem qualquer recorte dele, mas sim a essência metafísica que nele se expressa. Se toda situação empírica é uma objetivação fenomênica determinada da Vontade, então o verdadeiro músico, de acordo com o protótipo do gênio schopenhaueriano, é capaz de intuir imediatamente o movimento particular da Vontade que aí se expressa, de maneira a fazê-lo ressoar dentro de si mesmo, para depois devolvê-lo em forma de música ao ouvinte.

Mas justamente ao tentar distinguir shopenhauerianamente o processo criador do verdadeiro músico daquele meramente imitativo, próprio das artes plásticas, Wagner dá um passo claro e firme para além de Schopenhauer:

Daquele [ato de criação dos artistas visuais] devemos reconhecer como pré-condição a contemplação dos objetos pura e livre da vontade... Ao músico, não se apresenta nenhum tal objeto para que ele, através da pura contemplação o eleve à Ideia, pois sua música é, ela mesma, uma Ideia do mundo, na qual este apresenta imediatamente sua essência, enquanto que nas outras artes esta essência se apresenta apenas mediada pelo conhecimento . $^{5}$.

Um parágrafo antes Wagner já havia utilizado a estranha expressão Ideia do mundo para referir-se à essência da música:

5 Wagner, R., Beethoven, in Sämtliche Schriften und Dichtungen, Band 9, p.72. Leipzig, Breitkopf \& Härtel, 1911. 
Que o elemento da música, porém, já é uma Ideia do mundo, não mais por nós vista, mas sentida na mais profunda consciência, isto aprendemos cabalmente com Schopenhauer. ${ }^{6}$

Seria de se perguntar em que lugar Schopenhauer nos ensina isto, vez que relativamente aos termos de sua filosofia a mencionada expressão constitui clara aberração. E deve-se notar que a dissonância entre Wagner e Schopenhauer é muito mais teórica do que terminológica, pois acabamos de ler que nessa Ideia do mundo que é a música, “...[o mundo] apresenta imediatamente sua essência, enquanto que nas outras artes esta essência se apresenta apenas mediada pelo conhecimento".

Como se sabe, para Schopenhauer a música não é nenhuma Ideia do mundo, mas sim uma cópia direta da Vontade, e portanto uma representação da mesma. Exatamente por isso, sua apreensão estética é um ato do conhecimento, se bem que não mais do conhecimento de uma ideia, como ocorre no caso das artes visuais, mas sim da própria Vontade. Segundo o $O$ mundo como Vontade e representação, a música representa a Vontade diretamente, enquanto que as outras artes o fazem apenas por intermédio da ideia. Mas precisamente por se tratar de representações em ambos os casos, o efeito da música, diz Schopenhauer, “...é no todo semelhante ao das ouras artes, apenas mais vigoroso, mais rápido, mais necessário e infalível"”.

Wagner, contudo, deseja abrir um fosso muito mais profundo entre o efeito da música e o das outras artes, mesmo que para isso tenha de ignorar as condições de possibilidades estabelecidas por Schopenhauer para toda experiência estética:

Devemos entender isso como se a vontade individual, que nas artes plásticas é trazida a silêncio por meio do puro contemplar, desperta no músico como Vontade universal...daí procede o efeito fundamentalmente diverso da música, em relação à pintura. Aqui, o mais profundo apaziguamento, lá a mais alta excitação da Vontade ${ }^{8}$.

Para Schopenhauer, entretanto, a experiência estética, qualquer que seja sua espécie, apenas pode dar-se quando nos comportamos como puros sujeitos do conhecimento, e, portanto, quando a Vontade é reduzida ao silêncio. Conforme estabelece claramente o capítulo 39 do segundo volume de sua obra capital, intitulado Para a metafísica da música, isto também é válido para a arte dos sons: 
Vemos portanto [na música]... os movimentos da Vontade transportados para o terreno da mera representação, que, enquanto tal, é o palco exclusivo das realizações de todas as belas artes; uma vez que estas exigem que a Vontade mesma permaneça fora do jogo e que nós sempre nos comportemos como puros sujeitos do conhecimento ...9

Se para Schopenhauer o sujeito puro do conhecimento, condição subjetiva de toda experiência estética, surge apenas com o abandono da consciência empírica que, subserviente à vontade individual, move-se apenas dentro dos limites do princípio de razão suficiente, para Wagner, a experiência propriamente musical requer também a supressão daquela última cidadela da subjetividade. O par sujeito-objeto, apontado por Schopenhauer como condição de toda representação é anulado, e, com ele, toda possível separação entre um eu e o mundo. A vontade individual silencia, mas apenas para ecoar no peito do indivíduo, em extático arrebatamento, como vontade universal. $\mathrm{O}$ véu ilusório da individuação é rasgado dando lugar ao sentimento profundo da unidade de todo o existente ${ }^{10}$.

Coerentemente com sua ideia da supressão da subjetividade na percepção estética da música, Wagner também declarará inadequado o conceito de beleza - cujo pressuposto subjetivo é, segundo Schopenhauer, a aparição do sujeito puro do conhecimento - para a apreensão teórica do verdadeiro sentido desta arte. Tal apreensão só seria possível, argumenta o músico, mediante o conceito do sublime ${ }^{l l}$. Mas com sua distinção taxativa entre o belo e o sublime, Wagner se distancia ainda mais de Schopenhauer, para quem o sublime nada mais é que uma modificação, ou tipo especial do belo. O objeto causador do sentimento do sublime, ensina $O$ mundo como Vontade e representação, é, por definição, belo, sendo porém ao mesmo tempo assustador, devido à virtual ameaça que representa à vida humana ${ }^{12}$. A experiência do sublime, temos então de concluir, consiste na apreensão da bela forma, acrescida, porém, de um outro elemento, a saber, o esforço consciente do sujeito para, não obstante

9 Die Welt als Wille und Vorstellung II, p.514 (paginação original). Leipzig, F.U. Brodhaus, 1859.

10 Eis aí já delineado aquele amálgama entre estética musical e o tema tipicamente romântico da unidade mística e primordial do indivíduo com a natureza que veremos aparecer na concepção nietzscheana do dionisíaco. O autor de $O$ nascimento da Tragédia, porém, de forma alguma imputará tal concepção da música a Schopenhauer.

11 Cf., Beethoven, pp. 77-78: "A música, em si e por si, apenas pode ser apreciada a partir da categoria do Sublime, uma vez que, desde o momento em que nos preenche, ela desperta o mais alto êxtase da consciência da ilimitação (des Bewußtseins der Schrankenlosigkeit). Já aquilo que, por outro lado, nos vem a acontecer somente em decorrência da imersão na contemplação das obras das artes plásticas, ... o exigido efeito da beleza sobre o ânimo, isto a música já opera desde sua primeira aparição, na medida em que imediatamente desvia o intelecto de toda apreensão das relações das coisas fora de nós e, como forma pura e livre de toda objetidade nos fecha ao mundo exterior, deixando-nos vislumbrar, em contrapartida, somente o nosso interior, assim como o interior de todas as coisas".

12 Cf. O mundo como Vontade e representação I, § 39. 
o temor naturalmente provocado pelo objeto contemplado, manter-se, como puro sujeito do conhecimento, imerso na contemplação da beleza. De maneira conseqüente, Schopenhauer opera apenas com o conceito de beleza em suas reflexões sobre a música, jamais a vinculando ao conceito de sublime, conceito que, aliás, sequer figura nos três principais e paradigmáticos textos que escreve sobre a arte dos sons ${ }^{13}$.

Mas, ainda destoando de seu pretenso mestre, Wagner permanece coerente consigo mesmo, pois a apreensão da forma, bela ou não, pressupõe sempre um sujeito que a apreende, e o sujeito é precisamente o que deve ser suprimido pelo efeito mais essencial e necessário da verdadeira música. Não por acaso, Wagner, no mesmo contexto de suas reflexões sobre o sublime e o belo, deplora o caminho historicamente tomado pela música, especialmente no século XVIII, quando, extraviada por um cultivo excessivo dos aspectos formais e estruturais do discurso sonoro, teria abandonado sua mais alta missão e se distanciado de seu verdadeiro significado, muito mais sérios do que o frívolo prazer da percepção das belas formas. Sua defesa do sublime, em detrimento do belo, como parâmetro estético necessário para a apreciação do significado da música não é mais que a fundamentação filosófica desta apreciação histórica. Se Wagner não chega ao extremo de afirmar que a música possa prescindir da forma, deixa bastante claro que esta é elemento não essencial da verdadeira experiência musical. Por isso mesmo, a beleza, que tem na forma seu pressuposto, desempenha nessa experiência apenas um papel preliminar. Sua função é somente a de afastar-nos do mundo dos olhos e da visão, de despotencializar a consciência para a representação de qualquer objeto exterior, convidando o arrebatado ouvinte a defrontar-se diretamente com a essência recôndita de si mesmo e de todas as coisas, jacente para além de tempo e espaço. Dir-se-ia ser a beleza, para conservarmos os termos da analogia schopenhaueriana que Wagner tão engenhosamente utiliza em seu favor ${ }^{14}$, somente o passe hipnótico que prepara o transe clarividente propriamente dito, no qual já não se trata

13 Refiro-me ao capítulo 52 do primeiro volume de $O$ mundo como Vontade e representação, ao já mencionado capítulo 39 do segundo volume dessa obra e ao último capítulo do opúsculo Metafísica do belo (São Paulo, Editora Unesp, 2003), que em grande medida reproduz o primeiro texto aqui elencado.

14 A analogia aludida está em O mundo como Vontade e Representação (São Paulo, Ed. Unesp, 2005) § 52, p. 342 (paginação original: I 307). Diz ali Schopenhauer, na tradução de Jair Barboza: "O compositor manifesta a essência mais íntima do mundo, expressa a sabedoria mais profunda, numa linguagem não compreensível por sua razão: como um sonâmbulo magnético fornece informações sobre coisas das quais, desperto, não tem conceito algum." Sonâmbulo magnético, é, segundo esclarece nota do tradutor, expressão que designa pessoa hipnotizada. A "engenhosa utilização" wagneriana desta passagem, a que me refiro, consiste no recurso do compositor ao texto Ensaio sobre visões de espíritos e temas relacionados (Versuch über Geistersehn und was damit zusammenhängt), e será brevemente comentada na sequência de minha exposição. 
nem da bela forma nem de sua contemplação. A beleza, bem como as formas musicais que lhe são suporte, pertence apenas à parte exterior da música, pois são atinentes apenas à maneira como os sons se organizam no tempo.

Receio ter dito agora mesmo algo de bastante estranho, pois, não apenas para Schopenhauer, mas também (quero crer) para o leitor, a música é uma forma de organização dos sons no tempo! Wagner não é tão taxativo... Para ele, aquilo a que errôneamente chamamos música é apenas a forma pela qual a música se torna perceptível, é apenas seu reflexo no mundo da representação, ou melhor, em uma metade dele, o tempo. Livremente interpretando texto oriundo dos Parerga e Paralipomena que nada tem a ver com estética musical, Wagner ensina que a composição musical é semelhante à tradução dos sonhos mais profundos - e, por isso mesmo, mais apartados da consciência desperta e inalcançáveis à faculdade da memória - nos sonhos alegóricos de fácil memorização que antecedem imediatamente o despertar ${ }^{15}$. Também o compositor traduziria, mediante a organização dos sons no tempo, uma experiência musical vivenciada no mais recôndito recesso de seu ser, em que se lhe revelaria a essência atemporal do mundo. Pois o ato de compor precisaria ter seu início em uma imersão no elemento apontado por Wagner como o mais essencial da música, a harmonia, vale dizer, as relações de atração e repulsão, de concórdia e discórdia - em termos musicais: de consonância e dissonância -, que se estabelecem entre os sons, independentemente de seus fenômenos temporais e mesmo da passagem do tempo:

Enquanto a hamonia dos sons, não pertencente nem ao espaço nem ao tempo, permanece o mais próprio elemento da música, o músico, agora como formador, estende a mão, através da sucessão temporal rítmica de suas manifestações, ao mundo fenomênico da vigília, a fim de conferir-lhes inteligibilidade; assim como o sonho alegórico, que se vincula às representações costumeiras do indivíduo de tal forma que a consciência desperta e dirigida para o exterior... pode reter [a imagem onírica]. Mediante a organização rítmica de seus sons, o músico entra em contato com o mundo plástico intuível, .. ${ }^{16}$.

É portanto apenas a tradução fenomênica da eterna essência da música o que vem a dar origem ao elemento portador da temporalidade na música, o

15 De fato, a explicação do processo de composição musical a partir da tese enunciada em Ensaio sobre visões de espíritos e temas relacionados (ver nota anterior) sobre a tradução dos sonhos profundos nos sonhos analógicos é invenção exclusivamente wagneriana, bastante engenhosa, porém, a meu ver, incongruente com o sentido do texto de Schopenhauer. É de se supor que o trecho de $O$ mundo como Vontade e Representação citado na nota anterior tenha fornecido o ensejo para este intento, que entretanto não encontra justificação teórica no outro texto mencionado.

16 Wagner, op. cit. pp. 75-76. 
ritmo. De maneira que, com toda a coerência, o ritmo, substrato mais básico de toda possível estruturação sonora e sem o qual é impensável qualquer ideia de forma musical, é declarado elemento absolutamente externo e secundário da música. Como vimos, ele é apenas a mão que o compositor estende em direção ao mundo da representação a fim de comunicar e fixar o imo inefável da música.

O leitor atento terá percebido que chegamos assim a um paradoxo bem mais grave do que o referente à possibilidade da música programática. Pois vemos que aquilo que Schopenhauer - e não só ele! - considerava ser a música é, para Wagner, de fato representação, porém não mais representação da Vontade, e sim da verdadeira música, da música como Ideia essencial e atemporal do mundo. Já esta verdadeira música não mais pode representar a Vontade, pois, apartada do sensível, tem de resumir-se agora à muda contemplação face à face da essência do mundo, em cuja morada metafísica foi convidada a coabitar...

Levando-se em consideração a alegação sempre reiterada por Wagner de que sua filosofia da música se fundamenta diretamente na metafísica da Vontade, as considerações precedentes nos deixam diante de numerosas indagações, entre as quais uma, particularmente intrigante, assim se deixaria formular: serão as discrepâncias apontadas entre as estéticas musicais de Wagner e Schopenhauer derivadas de uma má leitura que o músico teria feito da obra do filósofo ou de uma deliberada tentativa wagneriana de apresentar uma concepção própria e original sobre a música como complemento estético específico à filosofia schopenhaueriana, a despeito da incongruência entre ambas?

Trata-se de problema de difícil resolução, e certamente haverá caminhos intermediários entre as duas posições. Sendo-me impossível fornecer aqui qualquer conclusão cabal neste ponto particular, contento-me em apenas apontar os motivos que me fazem tender bem mais à segunda hipótese que à primeira.

Destaque-se primeiramente que a própria destreza interpretativa que Wagner demonstra em seu Beethoven em relação ao texto de Schopenhauer torna um tanto problemática a tese da má leitura. Índice de tal destreza é, penso eu, inclusive o fato de que nos pontos capitais de sua exposição, ou seja, precisamente naqueles em que mais claramente se afasta da estética schopenhaueriana, o compositor não procure apoio nos textos "canônicos" 
de Schopenhauer sobre a música (talvez por ter plena consciência de que não se pode encontrar ali tal apoio!), mas sim em um texto que fala de coisas tão próximas à estética musical quanto visões de espíritos, sonambulismo, hipnose e sonhos premonitórios, cujos nome e procedência, aliás, se exime de indicar (ver notas 14 e 15).

Penso, porém, que a ideia de uma "adaptação" de Schopenhauer a uma concepção estética própria, por parte de Wagner, será mais fortemente sugerida pela consideração de que para este não é somente uma questão filosófica o que está em jogo, mas sim o próprio destino da arte musical. O músico evidentemente não envereda pela incerta senda da filosofia da música como "puro sujeito do conhecimento" filosófico, mas sim, e principalmente, como artista sumamente interessado em defender filosoficamente as suas próprias diretrizes artísticas. E certamente qualquer tentativa semelhante ganha bastante em peso na medida em que alguém como Schopenhauer, mesmo que indiretamente, parece prestar-lhe apoio....

Ora, as diretrizes estéticas wagnerianas apontam claramente na direção de um contínuo abandono da ideia de forma como princípio estruturante do discurso musical. Tal tendência, por sua vez pode ser vista como desdobramento histórico da já mencionada concepção romântica da música como mais íntima linguagem da alma, como veículo privilegiado de expressão de sentimentos e impulsos humanos. Como livre discurso da interioridade, a música romântica tenderá progressivamente a rejeitar todos os padrões formais de estruturação musical que "a priori”" e desde o exterior procurariam aprisionar a torrente dos sons dotando-a de inteligibilidade e racionalidade. A consequência estética desse anseio de liberdade é um contínuo enfraquecimento da ideia de forma musical, imperante no século XVIII como princípio organizador do discurso musical.

Mas, assim como no terreno do pensamento alemão do século XIX, vemos também na história da música a oposição entre uma corrente neoclássica e outra mais radicalmente romântica. Na primeira delas, entre cujos mais característicos representantes contam-se Mendelssohn e Brahms, procura-se conciliar o século XIX com o XVIII: a veemência do sentimento procura conviver com a preservação da forma. Na segunda, busca-se a máxima espontaneidade de um discurso que cria a si mesmo em cada momento a partir do interior, não se subordinando a nenhum padrão de estruturação musical pré-existente. Porém, quanto mais se enfraquecem os princípios puramente musicais de estruturação, tanto mais se manifesta, em certos compositores alinhados à tendência mais radicalmente romântica, o impulso à utilização do elemento dramático extra-musical (ou programático, segundo o jargão 
comum) como fio condutor do discurso sonoro. Por outro lado, quanto mais estreitamente esse discurso se vincula à sequência dramática, tanto mais o conceito de forma se mostra dispensável na prática efetiva da composição musical. A música de Wagner aparece como mais eloquente exemplo de ambos os fenômenos.

Surge assim a ideia wagneriana da melodia infinita, (o caos vertido em sons, o pólipo na música, como dirá Nietzsche ${ }^{17}$ ), cuja elevação filosófica à categoria de máximo paradigma da composição musical trará naturalmente consigo a exigência de que a forma seja declarada aspecto exterior e inessencial da música. Assim sendo, o ritmo, elemento possibilitador de qualquer estruturação formal dos sons no tempo, não poderá pertencer à essência da arte musical. Logo, tal essência não pode encontrar-se no tempo, já que do contrário teria de incluir em si o elemento rítmico. A essência da música deve, portanto, consistir em seu elemento que mais abstratamente e sem recurso à representação do tempo pode (ou parece poder) ser pensado, ou seja, a harmonia, wagnerianamente concebida como mera relação atemporal dos sons entre si.

Deixo ao leitor iniciado em música decidir se é realmente possível pensar em harmonia independentemente do ritmo, e se conceitos tão básicos como cadência ou progressão harmônica conservam algum sentido ao abstrairmos a passagem do tempo. O fato é que nem tais considerações nem sólidos conhecimentos de história da música impediram certo jovem filósofo wagneriano de, em sua primeira obra publicada, enxergar harmonia - que, como ele devia saber, teve de esperar a última fase da Idade Média para começar a engatinhar - na música grega arcaica, apontando-a inclusive como constituinte de seu elemento dionisíaco, e, portanto, mais essencial ${ }^{18}$. Podemos imaginar suas razões: se o drama musical wagneriano deve ser o renascimento da Tragédia grega, e se a essência da música wagneriana é a harmonia, então deve haver harmonia na música da Grécia trágica, ainda que seja aquela harmonia metafísica de que nos fala o compositor. A tanto podem levar entusiasmo e admiração juvenis! 
O entusiasmo, entretanto, terá fôlego curto: cedo Nietzsche se dará conta de que Wagner não lhe forneceria o trampolim adequado para seu pretendido salto para além de Schopenhauer. Se é possível falar em uma adesão quase que incondicional e apaixonada até a publicação de $O$ Nascimento da Tragédia, já os fragmentos póstumos de 1872, como também os dos anos seguintes, nos dão seríssimas razões para acreditar que o rompimento consumado com Humano, demasiado humano já se gestava desde bem antes, e que a Quarta Extemporânea não pode ter sido escrita sem graves conflitos de consciência.

De fato, este escrito festivo já termina com uma indireta. Para aquele povo futuro, diz Nietzsche, que lerá sua própria história na obra de Wagner, este será ...nomeadamente, não o que vê um futuro, como ele talvez nos quisesse parecer, mas um decifrador e transfigurador de um passado ${ }^{19}$. Wagner provavelmente não entendeu o sentido desta observação que Nietzsche lhe endereça ao final de um escrito que o homenageia; mas não pôde deixar de entendê-lo, dois anos mais tarde, em uma obra que sequer o menciona. Pois tudo indica que compreendeu perfeitamente quem, sobretudo, havia inspirado aquela caracterização que Humano, demasiado humano... faz do artista em geral como ser eminentemente voltado ao passado, herdeiro da religião e porta-voz da metafísica. Registre-se que algumas décadas depois, outro eminente ex-wagneriano retomou talvez inconscientemente o mote da Quarta Extemporânea e cunhou uma sentença que, por essa misteriosa afinidade que costuma unir espíritos musicais, faz ressoar os nomes de duas obras posteriores de Nietzsche. A música de Wagner, disse Claude Debussy é "um belo crepúsculo que foi confundido com uma aurora" 20 .

\section{Referências bibliográficas}

GOEDERT, G. - Nietzsche und Schopenhauer, in Nietzsche-Studien, Berlin, de Gruyter, 1977.

GRIFFITHS, Paul - A música moderna, Rio de Janeiro, Editora Zahar, 1987.

HONOLKA, K., et alii - Knaurs Weltgeschichte der Musik, Munique, Drömersche Verlagsanstalt Th. Knaur, 1968

NIETZSCHE, F., Die Geburt der Tragödie, in Kritische Studienausgabe, vol.1, edição de Colli e Montinari, Berlin-New York, Walter de Gruyter,1978.

Der Fall Wagner, Kritische Studienausgabe, vol.6, editado por Colli e Montinari, Berlin, de Gruyter, 1980.idem. 
Humano, demasiado Humano, tradução de Paulo César Souza, São Paulo, Companhia das Letras, 2001

SCHOPENHAUER- Die Welt als Wille und Vorstellung, Leipzig, Insel-Ausgabe, s/d. O Mundo como Vontde e Rpresentação. Tradução de Jair Barboza, São Paulo, Editora Unesp, 2005. Die Welt als Wille und Vorstellung II, Leipzig, F.U. Brodhaus, 1859. Metafísica do belo, Tradução de Jair Barboza, São Paulo, Editora Unesp, 2003.

WAGNER, R. Beethoven, in Sämtliche Schriften und Dichtungen, Band 9, Leipzig, Breitkopf \& Härtel, 1911. 